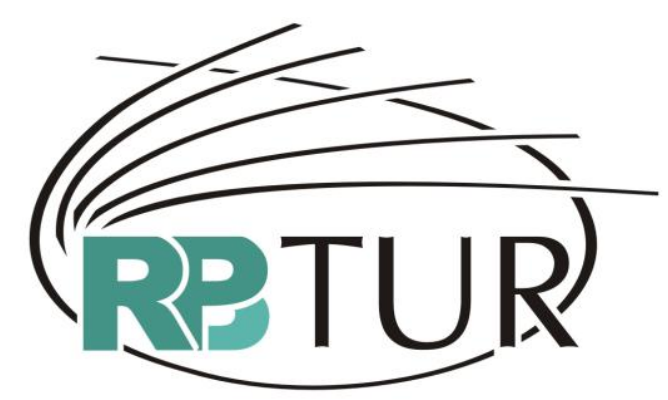

REVISTA BRASILEIRA DE PESQUISA EM TURISMO

\title{
TURISMO NO MUNICÍPIO DE BENTO GONÇALVES (RS): ANÁLISE DO DESENVOLVIMENTO DE UM DESTINO INDUTOR NO BRASIL
}

\author{
TOURISM AT BENTO GONÇALVES (RS, BRAZIL): \\ DEVELOPMENT ANALYSIS OF AN INDUCTOR DESTINATION \\ IN BRAZIL
}

\section{TURISMO EN EL MUNICIPIO DE BENTO GONÇALVES (RS, BRASIL): ANÁLISIS DEL DESARROLLO DE UNA DESTINACIÓN INDUCTORA EN BRASIL}

\author{
Edegar Luis Tomazzoni ${ }^{1}$ \\ Ana Maria Possamai \\ Rogério Lovatel ${ }^{3}$
}

\begin{abstract}
Resumo: o objetivo deste artigo é analisar o desenvolvimento turístico do município de Bento Gonçalves (RS), por meio de indicadores de desenvolvimento do setor. Para identificação de indicadores do desenvolvimento, aplicou-se instrumento com questões fechadas e relacionadas aos elementos de duas dimensões do turismo: desenvolvimento socioeconômico e gestão organizacional. Além da aplicação do instrumento, por meio de entrevistas junto a entidades e instituições do setor público e do setor privado no município de Bento Gonçalves (RS), o artigo é resultado de observação direta. O trabalho contempla também as expectativas do Ministério do Turismo de promoção de roteiros integrados e regionalização do turismo, por meio dos municípios indutores, entre os quais está o município em estudo. Como conclusões, tem-se que o município ainda enfrenta desafios de melhoria de sua infraestrutura e de sua oferta turística. Justifica-se, entretanto, que Bento Gonçalves seja um dos 65 destinos indutores do turismo do Brasil, em razão do empreendedorismo na realização de eventos, na criação e inovação de serviços e atrativos e nas estratégias de gestão e marketing turísticos.
\end{abstract}

${ }^{1}$ Doutor em Ciências da Comunicação com Ênfase em Turismo e Desenvolvimento Regional pela Universidade de São Paulo (USP). Professor e Pesquisador do Mestrado em Turismo da Universidade de Caxias do Sul (UCS). Email: edegarlt@terra.com.br

2 Mestre em Turismo pela Universidade de Caxias do Sul (UCS). Email: am.possamai@uol.com.br

${ }^{3}$ Especialista em Administração pela Universidade de Caxias do Sul (UCS). 
TOMAZZONI, Edegar Luis; POSSAMAI, Ana Maria; LOVATEL, Rodrigo. Turismo no município de Bento Gonçalves (RS): análise do desenvolvimento de um destino indutor no Brasil. Revista Brasileira de Pesquisa em Turismo. v.4, n.2, p.5-30, ago. 2010.

ISSN: $1982-6125$

Palavras-chave: Turismo. Indicadores. Desenvolvimento. Bento Gonçalves (RS).

Abstract: the objective of this article is to make an analysis of tourism in Bento Gonçalves City (Rio Grande do Sul State) through indicators of sector development. To identify the indicators an instrument with closed questions was applied based on elements of two dimension of tourism: social and economic development, and organizational management. Interviews with managers of private and public organizations were held, and also direct observation was conducted. The survey follows also the expectations of the Brazilian Ministry of Tourism for planning integrated itineraries and tourism regionalization through inductor cities. Some of the conclusions are that Bento Gonçalves faces challenges in improving its infrastructure and its tourist offer. It is however justified that Bento Gonçalves be among the 65 inductor destinations of Brazilian tourism due to its entrepreneurial spirit for events, creation and innovation of services and in strategies in management and tourist marketing.

Keywords: Tourism. Indicators. Development. Bento Gonçalves (RS, Brazil).

Resumen: el objetivo de este artículo es analizar el desarrollo turístico del municipio de Bento Gonçalves (RS, Brasil) a partir de los indicadores de desarrollo del sector. Para identificar los indicadores del desarrollo, se aplicó un instrumento con preguntas cerradas y relacionadas a los elementos de dos dimensiones del turismo: desarrollo socioeconómico y gestión organizacional. Además de la aplicación del instrumento, por medio de entrevistas en entidades e instituciones de los sectores público y privado de Bento Gonçalves, fue realizada observación directa. El trabajo también atiende las expectativas del Ministerio de Turismo, respecto a itinerarios integrados y a la regionalización del turismo a través de los municipios inductores, entre los cuales figura el área en estudio. Se concluye que la localidad todavía enfrenta desafíos para mejorar su infra-estructura y la oferta turística. Se justifica, no obstante, que Bento Gonçalves sea una de las 65 destinaciones inductoras de turismo en Brasil en función de su emprendeduría para la realización de eventos, creación, innovación de servicios y en las estrategias de gestión y mercadeo.

Palabras clave: Turismo, Indicadores, Desarrollo, Bento Gonçalves (RS, Brasil).

\section{Introdução}

Algumas das maiores dificuldades do turismo são a coleta, disponibilização e acesso a informações sobre seu desempenho. O Instituto Brasileiro de Turismo (EMBRATUR) faz enormes esforços para formar um banco de dados a respeito do turismo no Brasil, mas esbarra na ausência de uma logística de informações que se articule com os estados da federação, as regiões e os municípios. Outros problemas são: a recusa em fornecer dados precisos; a falta de organização dos poucos dados disponíveis; a falta de pesquisa com rigor metodológico; assim como de pesquisadores devidamente preparados. Estes e outros aspectos fazem com que os estudos a respeito dos 
TOMAZZONI, Edegar Luis; POSSAMAI, Ana Maria; LOVATEL, Rodrigo.

Turismo no município de Bento Gonçalves (RS): análise do desenvolvimento de um destino indutor no Brasil. Revista Brasileira de

Pesquisa em Turismo. v.4, n.2, p.5-30, ago. 2010.

ISSN: $1982-6125$

benefícios e impactos gerados pelo turismo estejam muito aquém das necessidades do planejamento.

O objetivo deste artigo é analisar o desenvolvimento turístico do município de Bento Gonçalves, identificando as principais suas necessidades e contribuir para a gestão do turismo local. Em razão disso, pretendeu-se, também, disponibilizar à municipalidade, às entidades e aos empreendedores, os resultados da pesquisa, que poderá ser utilizada como material de consulta para futuras análises e novas pesquisas acadêmicas pela Universidade, bem como pelos profissionais de turismo.

Para identificação de indicadores do desenvolvimento do turismo de Bento Gonçalves (RS) aplicou-se instrumento com questões fechadas e relacionadas aos elementos de duas dimensões do turismo: desenvolvimento socioeconômico e gestão organizacional. Além da aplicação do instrumento, por meio de entrevistas em entidades e instituições do setor público e do setor privado, no município de Bento Gonçalves (RS), o artigo é resultado de observação direta.

A pesquisa contemplou elementos básicos, como perfil econômico, infraestrutura e serviços gerais. Quanto à organização do turismo, abordamse: coordenação e gestão integrada; planejamento; atuação do setor privado; marketing, eventos e divulgação; configuração da oferta turística; desempenho e priorização do turismo; e integração regional.

Bento Gonçalves tem 383 quilômetros quadrados de área, população de 100 mil habitantes e figura entre as dez maiores economias do Rio Grande do Sul. É a capital brasileira do vinho e o maior e mais expressivo pólo moveleiro do Estado. Destaca-se pela qualidade de vida, sendo a primeira em Índice de Desenvolvimento Humano (IDH) do Rio Grande do Sul e a sexta do Brasil, conforme estudo da Organização das Nações Unidas (ONU) de 2003. O município é um dos 65 destinos indutores do país definidos pelo Estudo de Competitividade do Desenvolvimento Turístico Regional, realizado pelo Ministério do Turismo e pela Fundação Getúlio Vargas. 
TOMAZZONI, Edegar Luis; POSSAMAI, Ana Maria; LOVATEL, Rodrigo.

Turismo no município de Bento Gonçalves (RS): análise do desenvolvimento de um destino indutor no Brasil. Revista Brasileira de

Pesquisa em Turismo. v.4, n.2, p.5-30, ago. 2010.

ISSN: $1982-6125$

A pesquisa possibilita avaliar em que quesitos a localidade (destino) e as empresas nela instaladas devem melhorar, além de ser um instrumento eficiente para elaboração de planos de turismo municipais, bem como para atrair novos investidores. Dessa forma, é importante o incentivo à coleta e armazenamento de dados e de informações, tanto por parte das empresas, como por parte do poder público, com o intuito de conhecer a realidade e identificar as necessidades dos empreendedores e dos clientes do setor. Após a aplicação da pesquisa, os dados foram analisados com base nos elementos de maior relevância para o setor.

\section{Desenvolvimento Socioeconômico}

Para a delimitação espacial do desenvolvimento econômico, uma das premissas é a definição de critérios da contextualização geográfica, ou territorial. Por meio de interações sociais, as organizações especializam-se em determinadas atividades produtivas adaptando-se às condições do espaço físico (ANDRADE, 1987; CLEMENTE, 2000).

Um dos critérios para delimitar geograficamente um espaço ou território pode ser a decisão política. Além dos fatores geográficos e econômicos, a constituição de uma região é um fenômeno de natureza política (SANTOS, 2004). A economia espacial refere-se à análise dos tipos de atividades econômicas, suas localizações em relação a outras atividades, identificando aspectos referentes à proximidade, concentração e dispersão (BOUDEVILLE, 1973).

O enfoque do desenvolvimento econômico baseia-se em vantagens que geram exportações. As atividades exportadoras são motoras do desenvolvimento econômico com base em recursos naturais e em infraestrutura. A demanda externa pela produção local é fator de geração de renda, possibilitando o pagamento das importações e remuneração dos fatores produtivos. Cria-se, com esse processo, o fator mais importante para o desenvolvimento que é a especialização da divisão do trabalho, um campo de 
TOMAZZONI, Edegar Luis; POSSAMAI, Ana Maria; LOVATEL, Rodrigo. Turismo no município de Bento Gonçalves (RS): análise do desenvolvimento de um destino indutor no Brasil. Revista Brasileira de Pesquisa em Turismo. v.4, n.2, p.5-30, ago. 2010.

ISSN: $1982-6125$

conhecimento dos impactos da especialização sobre as aglomerações, considerando, principalmente, o processo de urbanização (PERROUX, 1967; HADDAD, 1975; ROCHEFORT, 1998).

A justificativa para os estudos da importância das aglomerações populacionais e das atividades econômicas são os ganhos de produtividade. Polèse (1998) os definiu como externalidades ou economias externas. As externalidades econômicas possibilitam ganhos de produtividade, em função da localização, redução de custos de produção e de transporte. Os custos são partilhados entre as organizações do aglomerado, e as facilidades são geradas pelo sistema econômico. Polèse (1998) salienta também a multiplicação das oportunidades de trocas e das especializações decorrentes das vantagens comparativas.

Os benefícios das externalidades econômicas diversificam-se e ampliamse em termos de geração de conhecimentos, por meio da distribuição de informações, criando-se um ambiente favorável à inovação em tecnologia, processos de produção, métodos de comercialização, capacitação e qualificação de recursos humanos. Vázquez Barquero (2001) defende a teoria do desenvolvimento endógeno, definido como uso do potencial existente no território pelas cidades e regiões, com base na referência da grande teoria do desenvolvimento.

A existência de externalidades é uma condição necessária para o desenvolvimento de uma cidade ou região. A rede de empresas industriais dá origem a uma multiplicidade de mercados internos e é, portanto, geradora de economias externas (VÁZQUEZ BARQUERO, 2001, p. 61).

Existe uma diferenciação entre economias de localização e economias de urbanização. Nas economias de localização consideram-se os resultados das interações entre as indústrias. Nas economias de urbanização obtêm-se vantagens em função do contexto geográfico das áreas ou centros urbanos. Para Polèse (1998), as indústrias das economias de urbanização obtêm vantagens que se revertem em ganhos de produtividade proporcionados pelos 
TOMAZZONI, Edegar Luis; POSSAMAI, Ana Maria; LOVATEL, Rodrigo.

Turismo no município de Bento Gonçalves (RS): análise do desenvolvimento de um destino indutor no Brasil. Revista Brasileira de Pesquisa em Turismo. v.4, n.2, p.5-30, ago. 2010.

ISSN: $1982-6125$

bens públicos. Como exemplos de bens - ou equipamentos - construídos pelo setor público, Polèse (1998) destaca estradas, portos, aeroportos, instalações elétricas, redes de esgoto. Como exemplo de serviços, tem-se: administração pública, educação, saúde, justiça e segurança.

Isso significa desenvolvimento de várias atividades econômicas e impulso a novas atividades. Polèse (1998) identifica como fatores que constituem o poder de retenção monetária: 1) diversificação da estrutura produtiva; 2) intensidade das transações entre os agentes econômicos; 3) distância em relação a outras regiões. Quanto mais desenvolvidos esses fatores, maiores as condições para incrementar o efeito multiplicador. A capacidade da região de manter-se atualizada em campos como capital físico, capital humano e conhecimento tecnológico é fator de competitividade para retenção de renda e potencialização do efeito multiplicador.

O conceito de arranjo produtivo local ( $A P L)$, que nasceu da idéia de aglomerado de empresas de um mesmo setor, ou de segmentos afins, proporciona subsídios para a gestão do desenvolvimento do turismo por várias organizações em diversas regiões do Brasil (VILLASCHI, 2003; REDESIST, 2008). A realidade das redes é dinâmica, e os sistemas de inovação funcionam de forma diferenciada, de acordo com os atributos do contexto regional, considerando-se os componentes ou elementos socioeconômicos, culturais e ambientais. Os critérios centrais do método de estudos organizacionais do APL são a territorialidade, a cooperação e os desafios e as dificuldades para a articulação das relações de intercâmbio entre as organizações (PAIVA, 2005).

\section{Desenvolvimento Socioeconômico e Turismo}

A fundamentação do turismo como atividade econômica, geradora de empregos e renda, se enfatiza em publicações da área, tanto em âmbito empresarial, quanto em âmbito acadêmico (URRY, 1995; BENI, 2001; PEARCE, 2002; TRIGO, 2005). 
TOMAZZONI, Edegar Luis; POSSAMAI, Ana Maria; LOVATEL, Rodrigo.

Turismo no município de Bento Gonçalves (RS): análise do desenvolvimento de um destino indutor no Brasil. Revista Brasileira de Pesquisa em Turismo. v.4, n.2, p.5-30, ago. 2010.

ISSN: $1982-6125$

Entre os mitos do turismo abordados por Lemos (1998), destaca-se o senso comum do desenvolvimento econômico proporcionado pela atividade. Para Lemos, o turismo é, entretanto, uma alternativa de crescimento econômico. Arrillaga, já em 1976, enfatizava que o turismo se destacava na produção científica pelos seus aspectos econômicos. A maior parte da bibliografia em turismo tratava dos seus atributos econômicos. Os incentivos e as regulamentações governamentais do setor se justificavam pela sua importância econômica.

Os efeitos do turismo são identificados por Wahab (1991). O balanço de pagamentos é um efeito direto resultante do intercâmbio turístico entre o país e o mercado internacional. O saldo é a diferença entre as receitas das vendas de serviços a estrangeiros em viagem no país e as despesas dos residentes em viagens ao exterior. Para Wahab (1991), o turismo contribui significativamente com a distribuição de renda e é o setor econômico que mais gera empregos, impulsionando o poder aquisitivo dos aglomerados industriais e comerciais. $\mathrm{O}$ efeito multiplicador do turismo é classificado por esse autor como impacto indireto e definido como a propriedade de gerar transações diversas e um montante maior do que a recebida de um turista. Outros exemplos de efeito indireto do turismo são as exportações de produtos secundários, resultantes das compras efetuadas pelos turistas e as receitas tributárias geradas para o setor público.

Para Lickorish (2000), o turismo cria mais postos de trabalho por unidade de capital do que uma unidade similar de capital investida em outro setor. Por ser uma atividade que abrange múltiplos setores, é difícil medir o número de ocupações no turismo. O volume de renda e o número de empregos são medidos por meio de amostragem. No mesmo sentido, Cooper et al (2001) argumentam que o turismo absorve quantidade expressiva de mão-de-obra, ao contrário de setores produtivos da economia como indústria e agricultura, nos quais ocorre dispensa de pessoal em razão dos avanços tecnológicos. Retoma o conceito de efeito multiplicador com base na idéia de 
TOMAZZONI, Edegar Luis; POSSAMAI, Ana Maria; LOVATEL, Rodrigo.

Turismo no município de Bento Gonçalves (RS): análise do desenvolvimento de um destino indutor no Brasil. Revista Brasileira de Pesquisa em Turismo. v.4, n.2, p.5-30, ago. 2010.

ISSN: $1982-6125$

interdependência entre os setores industriais de uma economia. A demanda final de um produto afeta a empresa e seus fornecedores.

Baidal (2004) analisa o turismo regional na Espanha, destacando que os resultados variam de acordo com as políticas regionais. Apesar do crescimento permanente de chegadas de turistas internacionais de 4,1 milhões em 1959 para 78,9 milhões em 2002, existiriam dificuldades de integração das dimensões setorial, territorial, econômica, sociocultural e ambiental do turismo e a distribuição de poderes e competências na gestão organizacional. Além disso, o planejamento regional do turismo espanhol não pode ser separado das políticas econômicas nacionais. Nesse modelo político-administrativo, deve, porém, prevalecer a intervenção das administrações locais e regionais.

O referencial teórico do estudo de Baidal (2004) destaca ainda que o planejamento do turismo tem incorporado as teorias da sustentabilidade e do desenvolvimento econômico de Hall (2000), Gunn (1994) e Inskeep (1991). A idéia da importância da sua orientação para a comunidade surgiu no final dos anos 1970, com os diversos trabalhos que criticam os efeitos socioculturais negativos do turismo com os estudos de De Kadt (1979) e Smith (1977). Para Baidal (2004), o planejamento estratégico mudou o foco do contexto dos negócios para o planejamento regional e urbano nos anos 1980 . Essa abordagem foi incorporada pelo turismo e enfatiza os seguintes elementos: análise do ambiente competitivo para definição das estratégias das empresas e das destinações; definição do tempo de planejamento com base em técnicas de previsão e prospecção; ênfase em participação social e na criação de canais de coordenação e cooperação entre parceiros investidores; valorização do planejamento como um processo permanente, flexível e integrado de gestão.

As estratégias sugeridas pelo autor reúnem uma oferta de serviços orientados ao turista e ao consumo, resumindo, uma cidade para ser turística deve possuir a infraestrutura compatível para receber os visitantes aliada a existência de atrativos, facilidade de acesso e fluxo, agradabilidade, imagem própria, sinalização e qualidade de vida para a própria população. 
TOMAZZONI, Edegar Luis; POSSAMAI, Ana Maria; LOVATEL, Rodrigo.

Turismo no município de Bento Gonçalves (RS): análise do desenvolvimento de um destino indutor no Brasil. Revista Brasileira de Pesquisa em Turismo. v.4, n.2, p.5-30, ago. 2010.

ISSN: $1982-6125$

Para ser turístico, um destino deve enquadrar-se a padrões mínimos de hospitalidade, a começar pela qualidade de vida da população anfitriã. Infraestrutura, acessos, terminais de viagem, sinalização, comércio e serviços de informações, meios de hospedagem e de alimentação constituem o ambiente favorável ao ingresso e permanência do turista por tempo compensador, tanto para ele quanto para a comunidade local (BENI, 2001).

Barretto (2001) esclarece que a infraestrutura compreende a base material, o conjunto de edificações, obras e serviços públicos que garantem o mínimo de conforto da vida urbana atual. A infraestrutura turística está constituída pela soma de:

- Infraestrutura de acesso (estradas, aeroportos, portos, rodoviárias, estações de trem);

- Infraestrutura básica urbana (ruas, sarjetas, iluminação pública etc.);

- Equipamentos turísticos, que são as construções que permitem a prestação de serviços turísticos (alojamentos, nos núcleos receptores; agencias, nos núcleos emissores; transportadoras em ambos);

- Equipamentos de apoio: instalações que permitem a prestação de serviços que não são exclusivamente turísticos, mas são quase indispensáveis para o desenvolvimento desta atividade (rede médico-hospitalar, rede de atenção ao automóvel, rede de entretenimento etc.).

Conforme apresentado no Relatório Brasil (2008), do Ministério do Turismo, para ter-se um produto turístico de qualidade, inicialmente, é preciso investir na melhoria da sociedade como um todo, construindo infraestrutura habitacional e sanitária para os cidadãos, propiciando melhores condições de saúde e alimentação. É preciso solucionar os problemas de base, em vez de esperar que a atividade turística seja a solução.

\section{Gestão, Cooperação, Marketing e Divulgação do Turismo}

Na dimensão organizacional, além das maneiras como se processam as relações entre as organizações, enfatiza-se a necessidade de que as relações 
TOMAZZONI, Edegar Luis; POSSAMAI, Ana Maria; LOVATEL, Rodrigo.

Turismo no município de Bento Gonçalves (RS): análise do desenvolvimento de um destino indutor no Brasil. Revista Brasileira de Pesquisa em Turismo. v.4, n.2, p.5-30, ago. 2010.

ISSN: $1982-6125$

se fundamentem e se consolidem com base em uma distribuição simétrica de poder. É preciso, portanto, um equilíbrio de forças, uma soma de interesses, de forma que se equilibrem as disputas por poder entre as organizações que constroem a coalizão da força-tarefa do sistema de gestão do turismo (SROUR, 1998; ADIZES, 2004; CARLZON, 2005).

Quanto aos papéis, funções e responsabilidades dos atores, não é somente no turismo que se apresentam questionamentos, dúvidas e indefinições sobre a atuação do setor público. Essa situação abrange e afeta as atividades econômicas de maneira geral. (HIRSCHMAN, 1961; RAMOS, 1989; FERRAZ et al, 2001; SANTOS, 2004).

Para Lemos (2005), o valor turístico tem origem nas relações sociais, mas está alicerçado nos bens e serviços de atração. O turismo apresenta-se como atividade econômica forte, porém, uma atividade cujo fator humano é indispensável e na qual estão envolvidos diferentes setores da cadeia produtiva. Seu cenário é amplo e envolve a esfera pública e privada, nas quais os papéis, funções e responsabilidades dos atores vão além das atividades diretas do turismo, abrangendo e afetando as atividades econômicas de maneira geral.

A cooperação em prol dos interesses coletivos é valorizada pela nova economia como elementos do capital social. A principal característica de um ambiente de geração de capital social é a cooperação, pois ela fornece condições para utilização eficaz dos recursos mobilizados e multiplica as energias para obter benefícios coletivos. (FUKUYAMA, 1996 ; PUTNAM, 2002). A atuação em benefício da coletividade pode visar ao próprio interesse, desde que a atitude seja orientada por padrões éticos, preservando-se a confiança e a credibilidade. A confiança é prioridade do capital social e é premissa da cooperação (COLEMAN, 1994; ARROW, 2000; COSTA, 2002; ALBAGLI e MACIEL, 2003).

Uma das condições mais evidenciadas pelos atores do turismo regional (empresários e gestores do setor) é a constante necessidade de divulgação dos atrativos, destinos e produtos e de implementação de estratégias de mercado. 
TOMAZZONI, Edegar Luis; POSSAMAI, Ana Maria; LOVATEL, Rodrigo.

Turismo no município de Bento Gonçalves (RS): análise do desenvolvimento de um destino indutor no Brasil. Revista Brasileira de

Pesquisa em Turismo. v.4, n.2, p.5-30, ago. 2010.

ISSN: $1982-6125$

É fundamental, portanto, que essa condição esteja presente nas análises, para entender que o discurso da mídia é fator de constituição da realidade turística. O turismo é divulgado como um dos campos que integram o macro e amplo contexto sociológico do lazer, como uma área da vida humana de múltiplas interfaces e abrangências. O referencial teórico da análise do discurso aplica-se à teoria e prática do turismo, identificando que os meios de comunicação e os instrumentos de marketing potencializam o discurso como estratégia de comercialização dos destinos turísticos.

Para a gestão da produção das mensagens difundidas pela mídia, é necessário ter presente os tipos de informações e as formas de comunicação dos diversos veículos. A divulgação do turismo tem objetivo comercial quando se realiza por meio da publicidade e da propaganda, que são estratégias convencionais de marketing utilizadas por outros setores de atividades. Observa-se, entretanto, que a maioria dos jornais de periodicidade diária publica seções ou cadernos especiais e exclusivos de turismo de edição semanal. Existem, ainda, revistas de turismo de periodicidade mensal e de circulação abrangente. A função dessas publicações é a venda de viagens nacionais e internacionais pelas organizações do setor, principalmente as agências e operadoras.

Mesmo que, muitas vezes, muito do conteúdo desses veículos seja de conotação editorial, isto é, de cunho jornalístico-informativo, sem foco explícito na comercialização, o objetivo é a venda de destinos, atrativos e serviços turísticos. Os veículos exclusivos, principalmente da mídia impressa - jornais e revistas -, dedicam expressivos espaços também a matérias de natureza essencialmente jornalístico-informativa e analítica. É frequente a publicação de comentários denotando questionamentos e críticas das relações do turismo com as políticas públicas, os temas ambientais, as identidades culturais, as iniciativas das organizações empresariais no desenvolvimento sustentável e a conjuntura econômica do setor.

$\mathrm{O}$ advento da internet potencializou e fomentou extraordinariamente a divulgação e a comercialização do turismo. A comunicação eletrônica em 
TOMAZZONI, Edegar Luis; POSSAMAI, Ana Maria; LOVATEL, Rodrigo.

Turismo no município de Bento Gonçalves (RS): análise do desenvolvimento de um destino indutor no Brasil. Revista Brasileira de Pesquisa em Turismo. v.4, n.2, p.5-30, ago. 2010.

ISSN: $1982-6125$

tempo real e em rede mundial tem sido um poderoso catalisador das estratégias de marketing e propaganda do turismo, como produto de consumo, além de constituir-se em importante instrumento operacional das organizações de mercado do setor.

A propaganda, um dos componentes do marketing turístico, é fator de projeção dos atributos naturais, culturais e históricos inseridos em roteiros, que aliados aos serviços de hospedagem e transportes compõem os tradicionais pacotes turísticos. A linguagem da propaganda turística é feita de termos que evocam sedução, beleza, harmonia, descontração e felicidade.

A divulgação turística por meio da mídia, com enfoque jornalístico ou comercial, seria, por si, um "atrativo turístico". A realidade do campo do turismo é fortemente constituída por esse tipo de discurso. O discurso da mídia contribui expressivamente para a existência do turismo, pois não é simplesmente fator de visibilidade dos destinos e atrativos. $O$ discurso expressa o ideal de conquista da qualidade de vida da pós-modernidade. A linguagem sedutora do discurso da mídia, para divulgação do turismo, é um conjunto de códigos, de signos que têm o poder de agrupar os atores que buscam a paz e a felicidade em outro lugar. (HARDY \& PALMER, 1998; PHILLIPS, 2003; FAIRCLOUGH, 2001).

\section{Regionalização do Turismo e Destinos Indutores}

O Programa de Regionalização do Turismo, Roteiros do Brasil, por meio do Plano Nacional de Turismo do Ministério do Turismo, propõe a estruturação de roteiros turísticos intermunicipais nas regiões turísticas brasileiras, com base nos princípios da cooperação, integração e sustentabilidade ambiental, econômica, sociocultural e político-institucional.

Em 2006, foram apresentados 396 roteiros turísticos, dos quais, 87 foram priorizados pelas Unidades da Federação, para obtenção de qualidade internacional e, conseqüentemente, o alcance das metas do Plano Nacional do Turismo. 
A partir dos 87 municípios, o Plano Nacional do Turismo identificou os destinos com capacidade de induzir o desenvolvimento regional. Isso significa que esses destinos serão priorizados para receber investimentos técnicos e financeiros do Ministério do Turismo e serão foco de articulações e busca de parcerias com outros ministérios e instituições.

Esses destinos têm a responsabilidade de propagar o desenvolvimento nos roteiros dos quais fazem parte e, consequentemente, nas regiões turísticas que perpassam. Serão ainda trabalhados para obtenção do padrão de qualidade internacional, constituindo assim modelos de desenvolvimento turístico regional.

Os destinos indutores deverão ser aqueles que possuem infraestrutura básica e turística e atrativos qualificados, que se caracterizem como núcleo receptor ou distribuidor de fluxos turísticos, isto é, capazes de atrair e distribuir um significativo número de turistas para seu entorno e dinamizar a economia do território em que estão inseridos.

O estudo de competitividade dos 65 Destinos Indutores do Turismo do Desenvolvimento Turístico Regional foi realizado por meio de uma parceria do Ministério do Turismo, Serviço Brasileiro de Apoio à Micro e Pequena Empresa (SEBRAE) e Fundação Getúlio Vargas.

O estudo possibilitou obter informações sobre a infraestrutura geral, transportes, acesso, equipamentos e serviços turísticos, marketing, sustentabilidade, entre outros elementos que permitem conhecer a conjuntura dos chamados, de acordo com o Plano Nacional de Turismo, destinos indutores do desenvolvimento turístico do país.

O objetivo da pesquisa realizada nos destinos pelo Ministério foi avaliar os aspectos que podem indicar a sua competitividade, para somar esforços para aprimorar as condições dos mesmos, visando à ampliação de sua competitividade e assim oferecer um atendimento de qualidade, além de focar as principais necessidades de investimentos e de servir de base para 0 planejamento de ações para o setor. 
TOMAZZONI, Edegar Luis; POSSAMAI, Ana Maria; LOVATEL, Rodrigo.

Turismo no município de Bento Gonçalves (RS): análise do desenvolvimento de um destino indutor no Brasil. Revista Brasileira de Pesquisa em Turismo. v.4, n.2, p.5-30, ago. 2010.

ISSN: $1982-6125$

No Estado do Rio Grande do Sul, foram contemplados a capital, Porto Alegre, e os municípios de Gramado e Bento Gonçalves, na região da Serra Gaúcha. Em função da escolha de Bento Gonçalves como destino indutor, outros 25 municípios da micro-região Uva e Vinho são beneficiados.

\section{Método}

Com base da revisão teórica, elaborou-se instrumento de coleta de indicadores do desenvolvimento do turismo do município de Bento Gonçalves.

Os principais indicadores para a análise da delimitação espacial do desenvolvimento socioeconômico foram: extensão territorial do município, atividades econômicas predominantes, características ambientais, participação da comunidade nas decisões governamentais.

$\mathrm{Na}$ revisão teórica do desenvolvimento socioeconômico do turismo, os indicadores destacados foram: configuração da oferta de serviços de meios de hospedagem e alimentação e taxas médias de ocupação, principais atrativos naturais e culturais, potencialidades vocações e oportunidades de negócios turísticos, números de turistas que ingressam anualmente, tempo de permanência no destino e seus gastos médios, empregos gerados pelo setor, dotação orçamentária municipal do turismo, atuação de instituições de ensino e pesquisa na formação e qualificação profissional, infraestrutura turística, abrangendo rodovias, sinalização terminais de viagem, bem como instalações básicas de saneamento e entretenimento.

Com base na revisão teórica da gestão, cooperação, marketing e divulgação do turismo, os indicadores foram: articulação das entidades para coordenação de iniciativas como eventos e campanhas promocionais, atuação e apoio da mídia em benefício das iniciativas, posicionamento do município em relação a outros pólos, aspectos e atributos turísticos mais evidenciados pelos veículos de comunicação, Realização de eventos (festas, feiras, congressos) e organização de calendário regional, captação de feiras e congressos, campanhas de promoção turística para redução da sazonalidade e aumento da 
TOMAZZONI, Edegar Luis; POSSAMAI, Ana Maria; LOVATEL, Rodrigo.

Turismo no município de Bento Gonçalves (RS): análise do desenvolvimento de um destino indutor no Brasil. Revista Brasileira de Pesquisa em Turismo. v.4, n.2, p.5-30, ago. 2010.

ISSN: $1982-6125$

ocupação, atuação de agências e de empresas especializadas em convenções, participações em feiras e eventos, adequação da oferta aos segmentos de mercado.

A aplicação foi realizada nas organizações públicas e privadas locais do setor: Secretaria Municipal de Turismo, Centro de Indústria e Comércio, Convention e Visitors Boureau, Sindicato de Hotéis e Restaurantes e Associação de Municípios Turísticos da Região Uva e Vinho (ATUASERRA).

\section{Configuração da Oferta e Desempenho do Turismo de Bento Gonçalves (RS)}

De acordo com o Sindicato de Hotéis, Restaurantes, Bares e Similares (SHRBS) da Região Uva e Vinho, os números de meios de hospedagem do município de Bento Gonçalves são: 10 hotéis e 19 pousadas, que totalizam 1.080 unidades habitacionais e 2.321 leitos.

Entre os demais serviços privados para atender a demanda turística, têm-se 53 restaurantes, quatro lanchonetes, oito cafés, doze agências receptivas, nove estabelecimentos de lazer noturno, entre eles danceterias, boates e bares, e quatro locadoras de automóveis.

O número de turistas recebidos na cidade anualmente gira em torno de 500.000, sendo que, os meses considerados de alta temporada são janeiro e julho e de baixa temporada, agosto.

Conforme estudo anterior feito por entidades ligadas ao setor turístico, o valor médio gasto pelo turista em um dia incluindo pernoite em hotel, gira em torno de $\mathrm{R} \$ 1.000,00$. A taxa média de ocupação hoteleira informada pelo SHRBS é de $62,6 \%$ na alta temporada e de $44,68 \%$ na época de baixa.

O imposto gerado pelos hotéis para o município chegou a $\mathrm{R} \$ 322.000,00$ no ano de 2007. Além disso, o setor hoteleiro gera cerca de 2.000 empregos formais e outros 1.000 informais, porém, a média salarial é baixa, o salário mínimo normativo dessa categoria ficou em R\$466,40 em 2007. 
TOMAZZONI, Edegar Luis; POSSAMAI, Ana Maria; LOVATEL, Rodrigo.

Turismo no município de Bento Gonçalves (RS): análise do desenvolvimento de um destino indutor no Brasil. Revista Brasileira de Pesquisa em Turismo. v.4, n.2, p.5-30, ago. 2010.

ISSN: $1982-6125$

Os eventos movimentam o município em épocas de pouco fluxo turístico. Nesse sentido, o município vem realizando ações de captação de novos eventos para redução da sazonalidade do turismo, especialmente com a criação do Bento Convention Bureau.

Os recursos municipais para o turismo, no ano de 2008 , foram de $\mathrm{R} \$ 1,6$ milhão, $1,07 \%$ do orçamento total do município, considerados insuficientes em função do que o turismo representa para a cidade. O município tem recebido verbas do governo federal, através do Ministério do Turismo para desenvolvimento e incremento do setor. Também são realizados projetos em âmbito regional, com o apoio do Ministério.

Considerando-se, ainda, os eventos, a infraestrutura oferecida pelo Parque de Eventos é considerada uma das melhores do país, dispondo dos maiores espaços cobertos e climatizados da América Latina, com 50.282m², com capacidade para eventos de nível nacional e internacional, é comparado aos maiores e melhores centros de eventos do mundo.

Além do Parque de Eventos, alguns hotéis também possuem espaços para realização de congressos e seminários, como o Dall Onder Grande Hotel, Dall Onder Vittoria, Hotel Villa Michelon e Hotel Villa Europa.

Para o atendimento ao turista, existem apenas três postos de informações, um deles está localizado na entrada principal da cidade, junto à Pipa Pórtico, outro no centro, na Via Del Vino e no roteiro mais visitado, o Vale dos Vinhedos, sendo que dois deles são administrados pelo poder público municipal. Ainda com relação ao atendimento ao visitante, existem estabelecimentos e serviços com excesso de público e falta de capacidade de acomodação e atendimento. Isso ocorre especialmente com os hotéis e pousadas locais, em épocas de grandes feiras e eventos de nível nacional e internacional que a cidade sedia. Caso semelhante ocorre com os restaurantes da área central da cidade, onde no horário do almoço é preciso enfrentar filas para fazer uma refeição.

Ao se tratar de sinalização, conclui-se que faltam placas orientando a entrada e saída da cidade, bem como, nos pontos e atrativos turísticos e 
TOMAZZONI, Edegar Luis; POSSAMAI, Ana Maria; LOVATEL, Rodrigo.

Turismo no município de Bento Gonçalves (RS): análise do desenvolvimento de um destino indutor no Brasil. Revista Brasileira de

Pesquisa em Turismo. v.4, n.2, p.5-30, ago. 2010.

ISSN: $1982-6125$

acessos aos meios de hospedagem e outros serviços. Nesse caso, já existe um estudo, encomendando pelo poder público, para melhorias do trânsito e aumento da sinalização.

Tratando-se de divulgação e informações disponíveis na internet, o município possui um portal, administrado pela Prefeitura, onde é possível consultar assuntos referentes aos serviços e ações das diversas secretarias municipais, além de todo apoio necessário ao visitante.

\section{Cooperação, Gestão Municipal e Integração Regional do Turismo de Bento Gonçalves (RS)}

No setor público, a existência de uma secretaria exclusiva para o turismo tem sido importante para orientação, articulação das organizações privadas e desenvolvimento integrado do setor. Além dessa pasta na Prefeitura, tem-se o Conselho Municipal de Turismo (Comtur), do qual fazem parte os empresários locais, entidades públicas e privadas, com o intuito de discutir os planos e ações para o setor. A Secretaria de Turismo também promove encontros com os empreendedores, estudantes e comunidade local.

Além de órgãos e entidades voltadas especificamente ao turismo, as pessoas que trabalham nesse setor têm formação na área. No setor público, atuam funcionários concursados, portanto, capacitados para a elaboração e implementação de projetos. O mesmo vem ocorrendo no setor privado, que tem dado prioridade para a contratação de colaboradores qualificados.

O turismo foi destacado nas propostas de campanhas dos candidatos a prefeito e vereador nas últimas eleições municipais, o que mostra o interesse crescente e reconhecimento dos cidadãos pelo setor.

No âmbito regional, Bento Gonçalves situa-se na região turística da Uva e Vinho e faz parte de organizações e entidades que promovem o desenvolvimento do turismo em parceira com outras cidades, como a Associação de Turismo da Serra Nordeste (ATUASERRA) e Sindicato de Hotéis, Restaurantes, Bares e Similares. Por intermédio dessas entidades, tem 
TOMAZZONI, Edegar Luis; POSSAMAI, Ana Maria; LOVATEL, Rodrigo.

Turismo no município de Bento Gonçalves (RS): análise do desenvolvimento de um destino indutor no Brasil. Revista Brasileira de Pesquisa em Turismo. v.4, n.2, p.5-30, ago. 2010.

ISSN: $1982-6125$

realizado parceiras com os municípios da região, para divulgação e promoção, por meio de material impresso, web site e participação em feiras e eventos.

Além dessas entidades de abrangência regional, cada um dos principais roteiros turísticos do município conta com uma associação de turismo, que é integrada pelos empreendedores das localidades rurais. Essas associações vislumbram o turismo como gerador de desenvolvimento para as comunidades rurais e para as famílias que buscam na atividade uma alternativa de geração ou incremento da renda. As associações existentes são Associação de Produtores de Vinhos Finos do Vale dos Vinhedos - Aprovale, Associação Vinhos de Montanha - Asprovinho, Associação Caminhos de Pedra, Associação Vale das Antas.

Durante o estudo realizado junto à Secretaria de Turismo, pode-se constatar que esta não elaborou ainda um planejamento estratégico para a atividade no município. Mesmo com essas condições, constatou-se também que o turismo em Bento Gonçalves encontra-se em ascensão.

Apesar das dificuldades do setor turístico, como crise aérea, queda do dólar, lei seca, observa-se que o número de estabelecimentos criados nos últimos cinco anos é maior que o número de locais que fecharam num mesmo período de tempo. As estatísticas mostram que no setor de hospedagem, foram abertos pelo menos sete novos empreendimentos e nenhum fechou as portas, segundo o Sindicato de Hotéis, Restaurantes, Bares e Similares.

Como indicador positivo do desenvolvimento do setor turístico local, filiais de redes e grupos empresariais estrangeiros se instalaram em Bento Gonçalves e região, além dos empreendedores locais que expandiram seus negócios no ramo do turismo.

Existe oferta de cursos de capacitação e qualificação de profissionais na área turística, sendo eles: dois cursos de nível superior de turismo, oferecidos pela Universidade de Caxias do Sul e pela Faculdade Cenecista, um curso de Guia de Turismo, oferecido pelo SENAC e outros cursos técnicos para qualificar profissionais que atuam no atendimento, como recepcionistas e garçons e treinamentos aos profissionais que atuam na área da cozinha. 
TOMAZZONI, Edegar Luis; POSSAMAI, Ana Maria; LOVATEL, Rodrigo.

Turismo no município de Bento Gonçalves (RS): análise do desenvolvimento de um destino indutor no Brasil. Revista Brasileira de Pesquisa em Turismo. v.4, n.2, p.5-30, ago. 2010.

ISSN: $1982-6125$

A principal carência na capacitação da mão-de-obra local está no setor de atendimento específico ao visitante. Além disso, é preciso promover oficinas que divulguem os atrativos e serviços turísticos, pois nota-se que os profissionais que atuam no setor não estão preparados para orientar os visitantes.

Nesse sentido, a Prefeitura, por meio do órgão oficial de turismo, promove eventualmente, palestras de conscientização sobre a importância do turismo para a comunidade local. Essas palestras já foram ministradas em escolas, para a Brigada Militar, taxistas, entre outros.

Outra iniciativa da Secretaria de Turismo foram os curso de língua inglesa e espanhola, que aconteceram no ano de 2008, com o intuito de possibilitar as colaboradores dos meios de hospedagem, gastronomia, atrativos e serviços turísticos, aprender noções básicas de línguas estrangeiras, para melhorar a comunicação com os turistas.

Como indicador do desenvolvimento da atividade turística do município, identifica-se a visita de comitivas de outras localidades para pesquisar e conhecer as realizações no setor, assim como viagens de atualização e missões técnicas realizadas pelos gestores e empreendedores locais, inclusive, ao exterior. O município também foi tema de palestras e objeto de estudos por estudantes do ensino superior, das universidades locais e da região.

\section{Marketing, Eventos e Divulgação do Turismo de Bento Gonçalves (RS)}

As pesquisas realizadas pela Secretaria de Turismo, nos postos de informações turísticas, apontam que os principais visitantes têm procedência da região metropolitana do Rio Grande do Sul, dos estados de São Paulo, Santa Catarina, Rio de Janeiro e Paraná.

Como estratégica de divulgação do município e região, o poder público e os empreendedores, têm realizado parcerias para participar dos principais eventos do setor turístico realizados no país, como ABAV, Festival de Turismo 
TOMAZZONI, Edegar Luis; POSSAMAI, Ana Maria; LOVATEL, Rodrigo.

Turismo no município de Bento Gonçalves (RS): análise do desenvolvimento de um destino indutor no Brasil. Revista Brasileira de Pesquisa em Turismo. v.4, n.2, p.5-30, ago. 2010.

ISSN: $1982-6125$

de Gramado, Salão Brasileiro do Turismo, Salão Gaúcho do Turismo, Expotchê, entre outros.

Os materiais usados na divulgação, produzidos pelo poder público, são o guia turístico, folder institucional, cartazes, calendários, vídeo, além de toda a folheteria produzida pelas associações de turismo e pelos empreendedores isoladamente.

Não existem veículos de comunicação local com programações específicas para o turismo, eventualmente são divulgadas nos jornais e emissores de rádio locais as ações da Prefeitura, por meio da Secretaria de Turismo ou dos empreendimentos.

Poucas são as pesquisas relacionadas ao turismo, realizadas em Bento Gonçalves, existe apenas um projeto para realização de um estudo da demanda, bem como, da satisfação do turista.

Tratando-se ainda da divulgação, existem inúmeras agências de viagens e turismo que atuam em todo o país com a venda de pacotes para o município e região, sendo os principais atrativos, "carros chefe", o passeio de trem Maria Fumaça e o Vale dos Vinhedos.

Nos últimos cinco anos, também foram criados e lançados no mercado novos produtos, serviços e atrativos turísticos, como o roteiro Vale do Rio das Antas, parque temático Epopéia Italiana, o Tour Via Del Vino, em fase de implementação, além de vinícolas que são abertas todos os anos e são o ponto fundamental do enoturismo.

O município de Bento Gonçalves tem se mantido na liderança regional do turismo, como principal destino na Região Uva e Vinho, sendo considerado inclusive, um dos principais destinos do Estado, juntamente com Gramado, na Região das Hortênsias.

Umas das deficiências constatadas no setor público é a inexistência de profissionais de comunicação e assessoria de imprensa dedicados, exclusivamente, ao turismo. A comunicação de toda a Prefeitura é feita pelo Departamento de Assessoria de Imprensa, através da qual, a Secretaria de Turismo tem enviado releases à imprensa regional e nacional. 
TOMAZZONI, Edegar Luis; POSSAMAI, Ana Maria; LOVATEL, Rodrigo.

Turismo no município de Bento Gonçalves (RS): análise do desenvolvimento de um destino indutor no Brasil. Revista Brasileira de Pesquisa em Turismo. v.4, n.2, p.5-30, ago. 2010.

ISSN: $1982-6125$

Eventualmente, são divulgadas matérias a nível nacional, estadual e com mais freqüência a nível regional. São utilizados jornais e televisão, abordando os exemplos positivos do turismo, desenvolvidos no município e região.

Outra forma utilizada para a divulgação é a distribuição de material gráfico às agências de viagens e turismo de todo o país. Ao se tratar de internet, o órgão oficial de turismo não possui um web site específico para o setor, este é um projeto que está em andamento, no momento a Prefeitura disponibiliza um espaço para o turismo no site oficial do município.

O município tem firmado parcerias com outros municípios da região e do Estado na produção de material de divulgação turística, é o caso do roteiro Caminhos Temperados, lançado recentemente. Esse roteiro integra as cidades de Porto Alegre, Gramado e Bento Gonçalves. Além dessa parceria, Bento Gonçalves integra a Associação de Turismo da Serra Nordeste, através da qual, são produzidos materiais e tem-se participado de eventos com o intuito de divulgar a região Uva e Vinho.

Os aspectos de maior destaque quando se trata de divulgação são: os eventos que acontecem com freqüência na cidade, os roteiros de renome nacional já consolidados como atrativos, bem como a gastronomia e os meios de hospedagem.

Nos últimos dois anos, realizaram-se os eventos: Feira Nacional do Vinho (FENAVINHO), de abrangência nacional; Festa da Colheita, de abrangência estadual; FRUTTI FEST, de abrangência regional; Exposição de Produtos (EXPOBENTO), de abrangência estadual; Feira Internacional de Máquinas para a Indústria Moveleira (FIMMA), Feira Internacional de Móveis MOVELSUL e Feira Internacional de Equipamentos e Tecnologia para o Meio Ambiente (FIEMA), de abrangência internacional. Esses eventos fazem parte do calendário oficial de eventos do país. Recentemente foi lançado o Bento Convention Bureau, entidade que conta com profissionais dedicados à captação de eventos.

As pesquisas de satisfação do turista são realizadas de forma isolada pelos empreendedores, não ocorrendo posteriormente à unificação dessas 
TOMAZZONI, Edegar Luis; POSSAMAI, Ana Maria; LOVATEL, Rodrigo.

Turismo no município de Bento Gonçalves (RS): análise do desenvolvimento de um destino indutor no Brasil. Revista Brasileira de Pesquisa em Turismo. v.4, n.2, p.5-30, ago. 2010.

ISSN: $1982-6125$

informações, de modo que, não existem dados que apontem como está a oferta dos produtos e serviços turísticos na opinião dos visitantes.

\section{Conclusão}

A pesquisa realizada para este artigo, aplicada em Bento Gonçalves (RS), proporciona subsídios para promover a integração da atividade em âmbito regional, contemplando também as expectativas do Ministério do Turismo de promoção de roteiros integrados e regionalização do turismo.

A definição do município de Bento Gonçalves como um dos 65 destinos indutores do país, pelo Estudo de Competitividade do Desenvolvimento Turístico Regional, realizado pelo Ministério do Turismo e Fundação Getúlio Vargas, é em razão da diversidade de sua oferta e infraestrutura turística adequada. O município é indutor porque tem vantagens comparativas em relação aos demais destinos do estado.

Após o levantamento dos dados por meio da pesquisa de indicadores, foi possível traçar um panorama do município de Bento Gonçalves e identificar pontos fortes e fracos do turismo. De acordo com os profissionais da equipe da Secretaria de Turismo local, a pesquisa foi relevante para a coleta de dados que possibilitaram melhoria do planejamento e da gestão do turismo, inclusive, para habilitá-lo a campo sede da Copa do Mundo 2014. Esse fato confirma a importância da realização de estudos desta natureza.

Os resultados apontaram, como principais pontos fracos, os acessos rodoviário, aeroportuário e ferroviário. A inexistência de planejamento e de um plano de marketing para o turismo também foram aspectos considerados deficientes. Este último decorre da inexistência de estatísticas, pesquisas de demanda, da oferta e dos impactos causados pela atividade.

A falta de conhecimento da população sobre a importância da atividade turística para o município foi outro problema identificado, o que impossibilita trabalhar de forma integrada à sociedade. Nesse contexto, é necessário retomar a questão da conscientização turística, tanto das autoridades locais, 
TOMAZZONI, Edegar Luis; POSSAMAI, Ana Maria; LOVATEL, Rodrigo.

Turismo no município de Bento Gonçalves (RS): análise do desenvolvimento de um destino indutor no Brasil. Revista Brasileira de

Pesquisa em Turismo. v.4, n.2, p.5-30, ago. 2010.

ISSN: $1982-6125$

dos políticos, dos empresários quanto da população, que devem acreditar que a atividade pode ser geradora de emprego e renda, além de proporcionar melhorias estruturais $e$, consequentemente, da qualidade de vida. A participação e a cooperação dos atores da comunidade local são fundamentais para o maior desenvolvimento endógeno do setor.

A baixa qualificação dos profissionais que atuam no atendimento ao visitante e a falta de novos e diversificados empreendimentos foi outra deficiência apontada pelas pesquisas, sendo que, para o setor, são fatores fundamentais por estarem diretamente relacionados à satisfação do turista. Esse é um dos aspectos imprescindíveis do marketing turístico.

São consideradas como principais ameaças ao destino os roteiros vizinhos já consolidados, entre eles, a Região das Hortênsias, as capitais dos países próximos, como Montevidéu e Buenos Aires, além da concorrência com outros estados brasileiros, considerando-se que o país que tem o litoral como forte atrativo. Trata-se, portanto, de outro aspecto relevante a ser contemplado pela gestão do marketing turístico local. É preciso, porém, que se fortaleça a integração regional do município com os demais municípios da região da Serra Gaúcha, com base nas dimensões e elementos do Arranjo Produtivo Local de Turismo, especialmente, a cooperação e o capital social.

A dotação orçamentária, ou os recursos financeiros devem ser suficientes para investir em ações que proporcionem a melhor relação custo-benefício para cidade em termos turísticos, porém, a carência de recursos para a realização e participação em eventos e para produção de material de divulgação aparece como uma das principais dificuldades em marketing. A falta de infraestrutura física da Secretaria de Turismo e, principalmente, dos postos de informações turísticas, também figuram entre as limitações encontradas. Tratando-se do órgão oficial de turismo, a principal dificuldade encontra-se na falta de recursos para execução dos projetos.

As pesquisas, entretanto, mostram que a maioria dos aspectos analisados apresentaram resultados positivos. Entre eles, estão a infraestrutura geral, serviços e equipamentos turísticos, atrativos locais, 
TOMAZZONI, Edegar Luis; POSSAMAI, Ana Maria; LOVATEL, Rodrigo.

Turismo no município de Bento Gonçalves (RS): análise do desenvolvimento de um destino indutor no Brasil. Revista Brasileira de Pesquisa em Turismo. v.4, n.2, p.5-30, ago. 2010.

ISSN: $1982-6125$

políticas públicas, cooperação regional, economia local, capacidade empresarial, aspectos ambientais e culturais.

O destino Bento Gonçalves apresenta atrativos para atrair visitantes nas quatro estações. A cidade possui o segundo maior parque de eventos do Brasil, totalmente climatizado, representando infraestrutura competitiva para sediar eventos, além de estar próxima dos grandes centros emissores.

É possível observar que Bento Gonçalves encontra-se em fase de ascensão do desenvolvimento. Essa ideia envolve uma série de fatores, como melhoria da qualidade de vida, progresso, tecnologia, recursos, industrialização, desenvolvimento agrícola, educação e cultura, e, especialmente, próprio turismo, que desponta como uma alternativa promissora. O turismo contribui significativamente para o desenvolvimento socioeconômico, por meio de indicadores quantitativos, como geração de empregos e renda e de indicadores qualitativos, como projeção da imagem por meio da mídia e fortalecimento da autoestima da comunidade local. Os resultados positivos da pesquisa validam a escolha do município pelo Ministério do Turismo como um dos 65 destinos indutores do turismo do país.

Apesar de os resultados serem positivos, os envolvidos na atividade turística, em todas as esferas devem priorizar a iniciativa, o dinamismo e a inovação. É preciso dar continuidade aos projetos em andamento e planejar ações para atingir os resultados esperados para o setor. A continuidade das políticas públicas e a cooperação entre os atores, tanto em âmbito municipal quanto em âmbito regional, são fundamentais para que o turismo continue atraindo visitantes e trazendo benefícios à população local de forma sustentável, por meio da articulação entre poder público, empresários, entidades do setor e organizações da comunidade.

\section{Referências}

ADIZES, I.. Gerenciando os ciclos de vida das organizações. São Paulo: Pearson, 2004. 
TOMAZZONI, Edegar Luis; POSSAMAI, Ana Maria; LOVATEL, Rodrigo. Turismo no município de Bento Gonçalves (RS): análise do desenvolvimento de um destino indutor no Brasil. Revista Brasileira de Pesquisa em Turismo. v.4, n.2, p.5-30, ago. 2010.

ISSN: $1982-6125$

ALBAGLI, S.; MACIEL, M. L.. Capital social e desenvolvimento local. In: Pequena empresa; cooperação e desenvolvimento local. Rio de Janeiro: Relume Damurá, 2003.

ANDRADE, M. C. de. Espaço, polarização e desenvolvimento: uma introdução à economia regional. São Paulo: Atlas, 1987.

ARROW, K. J. Observation on social capital. In: DASGUPTA, P.; SERAGELDIN, I. Social capital: a multifaced perspective. Washington, D.C.: The World Bank, 2000.

BARRETTO, M.. Manual de iniciação ao estudo do turismo. Campinas: Papirus, 2001.

BOUDEVILLE, J. R.. Os espaços econômicos. São Paulo: Difel, 1973.

BENI, M. C.. Análise estrutural do turismo. São Paulo: Senac São Paulo, 2001.

CARLZON, J.. A hora da verdade: o clássico sobre liderança que revolucionou a administração de empresas. Rio de Janeiro: Sextante, 2005.

CLEMENTE, A.; HIGACHI, H. Y.. Economia e desenvolvimento regional. São Paulo: Atlas, 2000.

COSTA, A. C. G.. Por uma cultura de cooperação. Brasília: SEBRAE, 2002.

COLEMAN, J. S.. Foundation of social theory. Cambridge MA: Harvard University Press, 1994.

FUKUYAMA, F.. Confiança: as virtudes sociais e a criação da prosperidade. Rio de Janeiro: Rocco, 1996.

KRIPPENDORF, J.. Sociologia do turismo. Rio de Janeiro: Civilização Brasileira, 2003.

PAIVA, C. A.. Aglomerações, arranjos e sistemas produtivos locais: o que são, como se diferenciam e quais as políticas mais adequadas ao seu desenvolvimento. Redes. Vol. 10, n. 3. Santa Cruz do Sul: Edunisc, 2005.

PEARCE, D.; BUTLER, R.. Desenvolvimento em turismo. São Paulo: Contexto, 2002.

PERROUX, F.. A economia do século XX. Lisboa: Livraria Morais Editora, 1967. POLÈSE, M.. Economia urbana e regional: lógica espacial das transformações econômicas. Coimbra: APDR, 1998.

PUTNAM, R. D.. Comunidade e democracia: a experiência da Itália moderna. Rio de Janeiro: Fundação Getúlio Vargas, 2002.

ROCHEFORT, M.. Redes e sistemas: ensinando sobre o urbano e a região. São Paulo: Hucitec, 1998.

SANTOS, M.. Por uma geografia nova. São Paulo: EDUSP, 2004.

SROUR, R. H.. Poder, cultura e ética nas organizações. Rio de Janeiro: Campus, 1998.

TRIGO, L. G.. Análises regionais e globais do turismo brasileiro. São Paulo: Roca, 2005.

URRY, J.. Consuming places. New York: Routledge, 1995.

VÁZQUEZ BARQUERO, A.. Desenvolvimento endógeno em tempos de globalização. Porto Alegre: UFRGS Editora, 2001.

VILLASCHI, A.. Arranjos produtivos locais. Universidade Federal do Rio de Janeiro: RedeSist, 2003. 
TOMAZZONI, Edegar Luis; POSSAMAI, Ana Maria; LOVATEL, Rodrigo. Turismo no município de Bento Gonçalves (RS): análise do desenvolvimento de um destino indutor no Brasil. Revista Brasileira de Pesquisa em Turismo. v.4, n.2, p.5-30, ago. 2010.

ISSN: $1982-6125$

Artigo recebido em fevereiro de 2010.

Aprovado para publicação em agosto de 2010. 